\title{
LA ESPAÑA DE FRANCO Y LOS JUDÍOS
}

\author{
Antonio Marquina ${ }^{1}$ \\ Director de UNISCI
}

Title in English: "Franco's Spain and the Jews"

Copyright @ C UNISCI, 2014.

Las opiniones expresadas en estos artículos son propias de sus autores, y no reflejan necesariamente la opinión de UNISCI. The views expressed in these articles are those of the authors, and do not necessarily reflect the views of UNISCI.

\section{Introducción}

La tesis tradicional sobre el papel de la España de Franco con respecto a los judíos ha sido sometida a profunda revisión en los últimos años. No obstante, han perdurado un conjunto de estereotipos, ampliamente mantenidos desde el final de la Segunda Guerra Mundial, que han resultado difíciles de modificar, a pesar de las nuevas evidencias aparecidas en archivos nacionales y extranjeros. El proceso de asunción de estas nuevas evidencias por expertos e investigadores, por el público en general, y hasta el mundo judío en general ha resultado lento y sometido incluso a notables sorpresas y retrocesos que no tienen mucho sentido y que, en ocasiones, son resultado de rápidas lecturas, cuando no de intereses poco confesables, como ocurrió con los resultados e investigaciones de la Comisión Oficial sobre transacciones de oro de Tercer Reich (1998), un escandaloso montaje con múltiples protagonistas, incluidos sorprendentemente diversos organismos y organizaciones judías.

En este trabajo expondremos algunas de las líneas que consideramos básicas de la política del régimen de Franco con los judíos. En primer término, señalaremos lo que consideramos el aspecto cardinal explicativo de la política del régimen de Franco hacia los judíos durante la Segunda Guerra Mundial: la experiencia de la guerra civil española. De la

\footnotetext{
${ }^{1}$ Antonio Marquina Barrio es Catedrático de Seguridad y Cooperación en las Relaciones Internacionales de la Universidad Complutense de Madrid, Director del Departamento de DIP y Relaciones Internacionales de la UCM, Director de UNISCI y Presidente del Foro Hispano-Argelino. Sus principales líneas de investigación son la seguridad en Europa, el Mediterráneo y Asia-Pacífico, y el control de armamentos.

Dirección: Departamento de Estudios Internacionales, Facultad de Ciencias Políticas y Sociología, UCM, Campus de Somosaguas, 28223 Madrid, España.

E-mail: marioant@cps.ucm.es.
} 
documentación hoy día disponible de embajadas y legaciones, nos permite asegurar sin ningún reparo que la casi totalidad de las comunidades judías existentes en España y las diversas comunidades judías, incluidas las sefarditas, establecidas en diversas partes del mundo, mostraron una notable hostilidad contra el bando nacionalista del general Franco. Un porcentaje significativo de judíos se alistó en las Brigadas Internacionales, contribuyendo a reforzar la tesis del "bolchevismo judío"2.

Al finalizar la guerra civil era muy pequeño el número de familias de judíos que quedaban en España. Buena parte de los judíos que habían entrado en España durante la II República habían optado por marcharse ante la incertidumbre generada por la guerra civil; otros hubieron de marcharse ante el temor de las sanciones por sus simpatías comunistas y republicanas; otros, muy pocos, optaron por quedarse en España. La Constitución y leyes de la República fueron suprimidas, desapareciendo con ello la libertad de cultos, y el Decreto de Expulsión de los Judíos de los Reyes Católicos volvió a tener virtualidad ${ }^{3}$.

En el plano interior, los efectos fueron de gran contundencia, las sinagogas de Madrid y Barcelona fueron cerradas; se prohibió la circuncisión, los cementerios y los matrimonios judíos; los niños judíos fueron obligados a aprender la religión católica en las escuelas; y conversiones de conveniencia se produjeron en Madrid y Barcelona. En otro orden, los judíos residentes en España fueron sometidos a una vigilancia especial y puestos en un registro especial policial en función de su "peligrosidad"4.

Es conocido el eslogan del bando nacional de "comunistas, judíos y masones" como principales enemigos de España. Este asunto se ha trivializado por diversos autores, como si fuera un eslogan sin importancia que se repitió hasta la saciedad en diversas publicaciones y por el Servicio Nacional de Propaganda, y que no tuvo consecuencias. Esta trivialización no es admisible. El propio Franco hablará en diversas ocasiones durante la guerra mundial en un sentido negativo de los judíos e incluso en 1943 envió al Papa Pío XII una supuesta carta personal del presidente Roosevelt al judío Zabrousky ${ }^{5}$ que denota una evidente aceptación del peligro judío.

Esta posición detectable en diversos niveles de la administración española, en especial el ministerio de Gobernación, el ministerio de Asuntos Exteriores y el ministerio del Ejército, así como de forma preeminente en la Falange y sus organizaciones, tendrá unas consecuencias muy negativas para los judíos, considerados como auténticos enemigos y un peligro para el Nuevo Estado español. Éstas se manifestarán de forma fehaciente tras el estallido de la Segunda Guerra Mundial en los trámites de concesión de pasaportes y visados, en la imposibilidad de venir a España para los cuatro mil o cinco mil judíos españoles residentes en Francia y en diversos estados ba1cánicos, en la sumisión de estas comunidades a las leyes antijudías alemanas, y en las consecuencias para estas comunidades, que desaparecieron en su mayoría víctimas del exterminios ${ }^{6}$.

\footnotetext{
${ }^{2}$ Avni, Haim (1982): España. Franco y los Judios, Madrid, Altalena, cita a Hugh Thomas quien da un número de 3.000 judíos alistados en las Brigadas Internacionales y a David Diamant quien aporta la cifra de 5.000. Un informe italiano de 1939 da la cifra de 6.000.

${ }^{3}$ Véanse las manifestaciones del Director General de Política Exterior, José María Doussinague, al nuncio Gaetano Cicognani en Actes et Documents du Saint Siege relatifs a la Seconde Guerre Mondiale, vol. 9, doc. 311.

${ }^{4}$ Véase Garzon, Jacobo, Israel: "El archivo judaico del franquismo", Raíces, no 33 (1997), pp.57-60. Más recientemente Reverte, Jorge M.: "La lista de Franco para el Holocausto", El País, 20 de junio de 2010. La cifra recogida en el censo es de 6.000 .

${ }^{5}$ La carta se puede consultar en el libro de Doussinague, José María (1949): España tenía razón, Madrid, Espasa Calpe.

${ }^{6}$ Véase la monografía de Marquina Antonio y Ospina Gloria Inés (1987): España y los judíos en el siglo XX,
} 


\section{Las posibilidades de tránsito por España}

Uno de los aspectos más enfatizados por las tesis tradicionales ha sido la afirmación de que España fue un país que ayudó a la salvación de 50.000 judíos, permitiéndoles la entrada en España. Esta aseveración merece una matización, pues no consta en los archivos españoles una tal magnanimidad en la concesión de visados de tránsito ni en 1940, con motivo de la derrota de Francia, ni en 1943, con motivo de la llegada de una segunda oleada de refugiados. En concreto, sobre 1940, la documentación del ministerio de Asuntos Exteriores sobre listas de ingresos ha desaparecido. Se sabe que los consulados españoles tenían orden de negar el pasaporte o visado a los judíos desafectos, es decir, la inmensa mayoría.

Sabemos también que hasta el reajuste de relaciones entre España y Alemania, tras la entrevista de Hendaya y la adhesión de España al Pacto de Acero, pacto más exigente que el tratado constitutivo de la OTAN, y que les comprometía a la instauración de "un orden nuevo en Europa", donde no había sitio para los judíos, existían unas directrices del gobierno establecidas en la Orden Circular 152 de 1 de mayo de 1940 sobre pasaportes y visados que sólo fragmentariamente conocemos. Aparentemente, los visados de tránsito podían otorgarlos las embajadas, legaciones y consulados sin consultar con Madrid, tras una criba individual muy cuidada. No estaba permitida la concesión de visados de tránsito a grupos ${ }^{7}$. Pero no conocemos otros aspectos significativos.

¿Bastaba un visado portugués para que las autoridades fronterizas españolas permitieran el tránsito por España? Parece ser que no, por lo que la tesis de que el primer secretario de la embajada de España en París, desplazado al sur de Francia, Eduardo Propper de Callejón se dedicó a sellar visados de tránsito parece ser válida. De lo contrario no se explica la validez de los miles de visados que Arístides Sousa Mendes selló y firmó en mayo y junio de 1940 en Burdeos y Bayona, válidos para acceder a Portugal. Pero en los múltiples papeles consultados referentes a diversos consulados españoles durante 1940 no se registra un movimiento mínimamente importante de concesión de visados a judíos. Y una vez que España se convierte en un país del Eje, con la adhesión al Pacto de Acero por el protocolo de Hendaya, se producirá una regulación más estricta de la entrada de extranjeros en España. El 8 de octubre de 1940, el Ministerio de Asuntos Exteriores, atendiendo a las indicaciones de la Dirección General de Seguridad, instó a aplicar de modo restrictivo las disposiciones establecidas en la Orden Circular de 1 de mayo de 1940. A partir de entonces, nadie podía entrar en España si no justificaba razonadamente el motivo del viaje y su solvencia política y económica.

En el caso de las solicitudes de visados de tránsito, los requisitos iban a ser muy meticulosos: nombres y apellidos, nacionalidad, pasaporte o certificado Nansen, edad, visado de la nación a donde se dirigían y visado de tránsito de todos los estados a recorrer. Si fuesen a embarcar en España, debían hacer constar el barco en el que iban a efectuar el viaje y el billete del pasaje. La solicitud se hacía mediante telegrama que había de pagarse por los interesados, pues, en caso contrario, se hacía por correo. La cuestión es que la respuesta se daba pasadas entre tres y seis semanas.

Solamente en casos de urgencia y muy excepcionales, que no requiriesen el envío de anejos, podían los representantes españoles solicitar por teléfono la autorización de visado. El tránsito así por España se convirtió en muy selectivo, añadiéndose a mediados de octubre la exigencia alemana, que el gobierno español aceptó, de no concesión de visados a polacos, belgas, holandeses y noruegos varones en edad militar, para evitar que se pudieran alistar en los ejércitos aliados.

Madrid, Espasa Calpe.

${ }^{7}$ Ibid., pp. 146-148. 
Los requisitos para los ciudadanos franceses serían igualmente rigurosos. El gobierno de Vichy decidió permitir el tránsito por España concediendo un visado de salida que fue muy restrictivo y estuvo plagado de obstáculos para evitar la emigración. España respetó esta medida del gobierno de Vichy hasta que el 4 de diciembre, seguramente por mutuo acuerdo, el Ministerio de Asuntos Exteriores español equiparó a los franceses a los no beligerantes, si eran mayores de cuarenta años y menores de dieciocho, siempre que cumpliesen los requisitos de estar en posesión de un visado portugués y un visado del país de destino.

A partir del 14 de noviembre, consolidada la situación, ya no fue necesario que las embajadas, legaciones y consulados consultasen con el ministerio el tránsito de los súbditos de países no-beligerantes. De la documentación consular consultada desde octubre de 1940, se detectan pocos movimientos en la concesión de visados, salvo en el caso de Suiza. Los países bajo la órbita alemana registran solo movimientos normales.

A esto cabe añadir la posición del gobierno portugués y del gobierno británico. El gobierno portugués decidió no conceder nuevos visados de tránsito, especialmente a judíos, hasta que los refugiados que llevaban meses en territorio portugués no fuesen evacuados. El Reino Unido no estaba dispuesto a admitir en territorio británico a estos refugiados y judíos, por motivos de seguridad y por motivos económicos, dadas las dificultades para su mantenimiento en el Reino Unido, salvo que fueran necesarios para apoyar el esfuerzo que la guerra había originado. A lo que venía a añadirse la falta de barcos de transporte. De este modo, el gobierno portugués, aun no siendo desfavorable a la concesión de nuevos visados de tránsito, se mantuvo imperturbable en su actitud: no se concederían nuevos visados de tránsito a refugiados de una nacionalidad mientras los refugiados que llevasen meses en Portugal no fuesen evacuados y se diesen seguridades de una pronta evacuación. Sólo en marzo de 1942 se consiguió el traslado de la práctica totalidad de los refugiados que habían llegado a Portugal tras el desastre de la derrota de Francia ${ }^{8}$.

En cuanto al período posterior de 1942-1943 y la nueva avalancha de refugiados con motivo de la ocupación de la Francia de Vichy, hay que hacer también algunas matizaciones. En este momento, al frente del Ministerio de Asuntos Exteriores estaba el general Jordana que luchó por enderezar la posición española y conseguir una mayor neutralidad. Jordana fue mucho más receptivo a las presiones aliadas que su antecesor $\mathrm{y}$, de hecho, la frontera se mantuvo abierta, salvo un breve período de tiempo a finales de marzo de 1943. Las embajadas de los Estados Unidos y del Reino Unido, así como las diversas organizaciones de auxilio establecidas en España pronto estuvieron desbordadas por la entrada de refugiados.

Si la tasa de llegadas semanales durante enero de 1943 fue de entre 500 y 700 refugiados, en febrero la tasa llegó a ser de 150 a 500 refugiados diarios. El gobierno español, pasado un tiempo, dio su visto bueno para el traslado de refugiados al norte de África y la concesión de visados para Portugal. Así, durante 1943, los aliados lograron evacuar a 16.000 refugiados franceses. Otros 4.500 refugiados, principalmente aliados y apátridas (1.400) fueron también evacuados por sus respectivas representaciones o agencias de socorro. Un número aproximado de 3.500 refugiados también serían evacuados durante el primer semestre de 1944.

Sobre las cifras de judíos que lograron atravesar los Pirineos desde la operación Torch al desembarco de Normandía existe una mayor aproximación entre los diversos testimonios y

\footnotetext{
${ }^{8}$ Ibidudem, pp.I48-149 y 164-168. Es interesante consultar el estudio de Avni, Haim:, "España y Portugal, su actitud respecto de los refugiados judíos durante la era nazi" en Klich, lgnacio y Rapoport, Mario (1997): Discriminación y Racismo en América Latina, Buenos Aires, Nuevohacer, pp. 258-262. El estudio deja pendiente la confirmación del número de visados y señala la apariencia de una imagen "incoherente y contradictoria".
} 
autores, haciéndola rondar entre 5.000 y 6.000. En este punto conviene señalar que el grueso de refugiados judíos que entraron en España lo hicieron en los primeros meses de 1943. En junio, la cadencia de entrada diaria estaba en uno o dos. Lo cual nos señala la dificultad de movimientos y los controles para los judíos en Francia ${ }^{9}$. Dentro de este contexto veamos la política española con respecto a los judíos nacionalizados españoles.

\section{La política de aprovechamiento económico}

Una vez que Alemania derrotó a Francia y dividió el país, empezaron a aplicarse a los judíos residentes en Francia las leyes antijudías alemanas. Las directrices del ministro de Asuntos Exteriores, Ramón Serrano Suñer fueron claras: los diplomáticos españoles no debían poner dificultades a la aplicación de medidas contra los judíos españoles; debían darse por enterados de estas medidas y conservar una actitud pasiva.

Cuando el Consulado español en París, con muy buen criterio legal, trató de oponerse a la aplicación de estas medidas a los 2.000 sefarditas españoles inscritos en el Consulado, con la documentación en regla, indicando que en España no existía legislación que estableciera una diferenciación de razas, Ramón Serrano Suñer volvió a repetir aquellas instrucciones, señalando además que esta respuesta a las autoridades alemanas no era aceptada y no se adecuaba al criterio del gobierno, añadiendo que "aunque en España no existe ley de razas, el gobierno español no puede poner dificultades aun a sus súbditos de origen judío para evitar se sometan a medidas generales".

Estas instrucciones serán el punto de referencia central de las instrucciones a otras embajadas y legaciones.

Junto a ello, los sefarditas españoles se inscribieron en un registro especial para que, de esta forma, sus bienes, empresas y cuentas corrientes no fueran objeto de expolio por parte de las autoridades de otros países, España iba a administrar estos bienes y en último término se aprovecharía de ellos antes de que lo hicieran otros países. Por ello, frente a la apariencia de un trato de favor, el ministerio de Asuntos Exteriores siempre consideró que no había trato de favor $^{10}$. De hecho, en París, el Banco de España en París se encargó de la administración de estos bienes. No obstante, no ha quedado documentación sobre sus actuaciones ni sobre los bienes que acabaron en sus arcas tras la desaparición de sus propietarios. Lo mismo se puede decir de otros países como Grecia. Aunque en este país se sabe que, tras la guerra, los supervivientes que volvieron a sus casas hicieron las reclamaciones pertinentes, dando lugar en algunos casos a situaciones desagradables.

En cuanto a las posibilidades de estos judíos españoles de marchar a España, la documentación hoy en día disponible señala dos aspectos no coincidentes. En el caso de Francia, donde estaba el grueso de los sefarditas nacionalizados españoles, no se accedió a la entrada de España de estos judíos, a pesar de las gestiones realizadas en $1941^{11}$. En el caso de otros países como Rumanía y Grecia las instrucciones no fueron negativas para los que lo solicitasen, se hubieran adherido a la causa nacional, ofreciesen garantías y solvencia moral y económica. Ahora bien, debían solicitarlo individualmente, detallando sus condiciones personales e indicando la población o poblaciones donde fueran a residir. No consta que las

\footnotetext{
9 Sobre este punto véase Marquina Antonio: "La Política del régimen de Franco hacia los sefarditas nacionalizados" en Klich, y Rapoport, op. cit., p. 249.

${ }^{10}$ La respuesta oral a la legislación suiza en Madrid es concluyente. Véase Marquina y Ospina, op. cit., p. 156.

${ }^{11}$ Ibid., pp. 150-156.
} 
listas de españoles inscritos en los consulados de estos países sufriesen variación ${ }^{12}$. En el caso de Bulgaria, no consta que se produjeran solicitudes, ni tampoco en Yugoeslavia ${ }^{13}$.

\section{Los judíos españoles ante la solución final}

Si en el período de Ramón Serrano Suñer como ministro de Asuntos Exteriores la política fue claramente obstruccionista, con flagrantes violaciones del derecho de nacionalidad, durante el período posterior del ministro Rafael Gómez Jordana, la situación no varió inicialmente de forma significativa, a pesar de haber comenzado "la solución final" y mostrar las autoridades alemanas mucha más prevención contra los judíos extranjeros residentes en diversos países por motivos de seguridad militar. Así, en enero de 1943, la embajada alemana en Madrid señaló que daban un plazo, hasta el 31 de marzo, para la repatriación de los judíos españoles de Francia, Bélgica y los Países Bajos. A partir de esta fecha no concederían un trato especial.

Significativamente, los planteamientos del director general de Política Exterior, José María Doussinague, siguieron la tónica anterior, tanto por lo que respecta a la consideración de bienes, como en lo que respecta a su entrada en España. De las varias soluciones propuestas, el ministro Jordana optó por buscar la forma de enviarlos a Salónica, Constantinopla, Esmirna o algún punto de los Ba1canes.

Pero esta solución se desechó por las dificultades y disposiciones existentes en esos países. Luego se solicitó el apoyo del American Joint Distribution Committee para que ayudara al paso por España en tránsito de estos judíos. Estos contactos se realizarán sobre la base de un planteamiento que la agencia estadounidense no considerará adecuado posteriormente, al percatarse de que eran judíos españoles y considerar, en consecuencia, que España debía hacerse cargo de sus nacionales.

Esto, a su vez, será una fuente de fricciones y retrasará la traída en tránsito de los sefarditas españoles, pues hasta que no saliera un grupo que había entrado con anterioridad no podía entrar en España otro grupo. Por otra parte, las dificultades de transporte eran ingentes tanto para la entrada como para la salida de España. Esto se complicó aún más cuando el Ministerio del Ejército obligó a quedarse en España a los judíos en edad militar que no hubieran hecho el servicio militar, dando lugar a nuevos retrasos en la salida de España. A lo que además se añadió la retirada de permisos de trabajo a judíos residentes en España desde 1933, algunos casados con españoles y teniendo hijos haciendo el servicio militar, y a los que se obligaba a marchar de España. Esto no se llevó a efecto por la negativa de las autoridades francesas 14 .

De este modo y en medio de obstrucciones de gran calado, como la negativa a aceptar la propuesta de Romero Radigales de repatriar a los sefarditas españoles de Salónica en barcos suecos de la Cruz Roja Internacional, o las propuestas alemanas de poner trenes especiales para traerlos a España, sólo aproximadamente una cuarta parte de los judíos sefarditas españoles residentes en Francia y en los Balcanes pudieron salvarse, pereciendo los demás en los campos de exterminio.

No obstante, hay que señalar un cambio tras el desembarco en Normandía, en buena parte motivado por el interés de mantener a su favor la opinión pública internacional, los Estados Unidos, y las organizaciones judías internacionales, pero manteniendo todavía la losa del Pacto de Acero. El caso más significativo fue la actuación de Ángel Sanz Briz en Hungría

\footnotetext{
${ }^{12}$ Ibid., pp. 159-161.

${ }^{13}$ Ibid., pp. 161-163.

${ }^{14}$ Ibid., pp. 180-211.
} 
y la protección de 1.898 judíos húngaros ${ }^{15}$. Sanz Briz actuó sin instrucciones, aunque no se apartó de las directrices generales del ministerio de Asuntos Exteriores establecidas por el general Gómez Jordana y por Doussinague-el Plan D- de seguimiento de la política vaticana y actuación conjunta con los Estados neutrales. La política de la legación española en Budapest vino determinada por las reuniones que el decano del cuerpo diplomático en Bucarest, el nuncio Angelo Rotta, estableció con los representantes de los Estados neutrales, donde se acordaron las medidas de protección a seguir, de ahí la similitud de las políticas de protección de estos Estados, incluida la actuación de Raoul Wallenberg.

Esta actuación en Hungría sirvió para labrar una imagen de la política española que, aunque no se correspondía con la realidad, caló en diversos grupos y comunidades judías. No obstante, la prevención de las autoridades españolas perduró en buena parte tras el final de la guerra mundial.

\section{La aceptación de una presencia organizada judía en España}

Al finalizar la Segunda Guerra Mundial, el gobierno de Franco trató de solucionar el asunto de la naturalización de los sefarditas y su entrada en España. Pero el criterio siguió siendo restrictivo. No se podían considerar españoles si no se habían acogido al Real Decreto de 20 de diciembre de 1924 e inscrito en el libro IV del Registro Civil la carta de naturaleza adquirida. No se autorizaba en caso alguno la entrada de sefarditas en España, aunque, se consideraba, las autoridades españolas habían de prestar la asistencia posible a los que fuesen ciudadanos españoles, facilitando su repatriación a los domicilios de origen si así lo solicitaban. La protección, no obstante, acabó manteniéndose, recibiendo un trato específico los sefarditas de Grecia y Egipto, en función de los convenios que España había suscrito con estos países y la terminación del régimen de capitulaciones ${ }^{16}$.

En otro orden, el régimen de Franco empezó a utilizar la supuesta protección a los judíos sefarditas durante la Segunda Guerra Mundial, publicando el folleto divulgativo "España y los judíos sefarditas" y movilizando a diversas comunidades sefarditas desconocedoras de la política real española durante la guerra, para conseguir el voto favorable del estado de Israel a España en la ONU, el reconocimiento mutuo, o la actitud favorable del Congreso Mundial Judío y congresistas estadounidenses. Esta política cristalizó en el mito del apoyo y protección de España a los judíos durante la Segunda Guerra Mundial, que ha llegado hasta nuestros días, facilitado por la protección española a los judíos españoles y no españoles en los países árabes con motivo de las guerras de Suez, de los Seis Días y del Yom Kippur ${ }^{17}$.

Mientras tanto, las pequeñas comunidades judías existentes en España empezaron a disfrutar de una cierta normalidad, dentro de las restricciones que imponía el artículo 6 del Fuero de los Españoles en cuestión de libertad de cultos, y más en concreto a los actos públicos. No obstante, se siguió excluyendo una presencia organizada judía, a pesar de los intentos de Daniel François Barukh. Sólo se permitió el funcionamiento de las sinagogas. Habrá de pasar una década, ya en pleno fragor de discusión de la libertad religiosa, para que el ministerio de Gobernación el 27 de febrero de 1965 apruebe los estatutos de la comunidad judía de Madrid, acogiéndose a la ley de asociaciones.

\footnotetext{
${ }^{15}$ Ibid., pp. 233-241.

${ }^{16}$ Ibid., pp. 211-222.

${ }^{17}$ Véase. de forma especial Lisbona, José Antonio (1993): Retorno a Sefarad, Barcelona, Riopiedras, pp. 181217.
} 
Este será el hito fundamental para el desarrollo posterior de las actividades de la comunidad judía en Madrid y, luego, de otras comunidades como la de Barcelona, Entre diciembre de 1967 y marzo de 1969, las comunidades judías terminaron inscribiéndose en el Registro de Asociaciones Confesionales.

La declaración Dignitatis humanae del Concilio Vaticano II y la ley de libertad religiosa de 28 de junio de 1967 habían facilitado este reconocimiento como grupos organizados. El salto había sido espectacular y cualitativo. Las comunidades judías en España salieron ya de las catacumbas. 